\section{OPEN ACCESS}

Edited by:

Nigel Turner

University of New South

Wales, Australia

Reviewed by:

Mark Vickers,

The University of Auckland,

New Zealand

Sarah M. Turpin-Nolan,

Monash University, Australia

*Correspondence:

Monica M. Telles

mmtelles@unifesp.br

Specialty section:

This article was submitted to

Obesity,

a section of the journa

Frontiers in Endocrinology

Received: 21 January 2019 Accepted: 18 April 2019

Published: 10 May 2019

Citation:

Hirata BKS, Cruz MM, de Sá RDCC,

Farias TSM, Machado MMF

Bueno AA, Alonso-Vale MIC and

Telles MM (2019) Potential

Anti-obesogenic Effects of Ginkgo biloba Observed in Epididymal White

Adipose Tissue of Obese Rats.

Front. Endocrinol. 10:284

doi: 10.3389/fendo.2019.00284

\title{
Potential Anti-obesogenic Effects of Ginkgo biloba Observed in Epididymal White Adipose Tissue of Obese Rats
}

\section{Bruna K. S. Hirata ${ }^{1}$, Maysa M. Cruz ${ }^{1}$, Roberta D. C. C. de Sá ${ }^{1}$, Talita S. M. Farias ${ }^{1}$, Meira M. F. Machado ${ }^{1}$, Allain A. Bueno ${ }^{2}$, Maria Isabel C. Alonso-Vale ${ }^{1}$ and Monica M. Telles ${ }^{1 *}$}

\footnotetext{
${ }^{1}$ Department of Biological Sciences, Institute of Environmental, Chemical and Pharmaceutical Sciences, Universidade Federal de São Paulo, Diadema, Brazil, ${ }^{2}$ Department of Biological Sciences, College of Health, Life and Environmental Sciences, University of Worcester, Worcester, United Kingdom
}

Exacerbated expansion of adipose tissue seen in diet-induced obesity leads to endocrine dysfunction and disturbance in adipokine secretion, with such abnormal profile positively associated with type 2 diabetes and other mild chronic inflammatory conditions. Ginkgo biloba extract (GbE), a mixture of polyphenols with antioxidant properties, has been recently investigated in a variety of experimental models of endocrine dysfunction, with several potentially beneficial effects identified, including improvement in insulin sensitivity in obese rats, and reduction of weight gain in ovariectomy-induced obesity and diet-induced obesity. The aim of this study was to investigate in high fat diet-induced obese male rats the effects of GbE supplementation for 2 weeks on adipocyte volume and adipose tissue lipid accumulation. GbE supplementation was effective in reducing energy intake in obese rats compared to the saline-treated placebo group. Epididymal adipocyte volume was reduced in GbE-supplemented rats, as were epididymal $\left[1-{ }^{14} \mathrm{C}\right]-$ acetate incorporation into fatty acids, perilipin (Plin 1) and fatty acid synthase (Fasn) $m R N A$, and FAS protein levels. Adipocyte hypertrophy in obesity is associated with insulin resistance, and in the present study we observed a reduction in the adipocyte volume of GbE-supplemented obese rats to dimensions equivalent to adipocytes from non-obese rats. GbE supplementation significantly reduced acetate accumulation and tended to reduce $\left[{ }^{3} \mathrm{H}\right]$-oleate incorporation, into epididymal adipose tissue, suggesting a potentially anti-obesogenic effect in longer term therapies. Further studies that investigate the effects of GbE supplementation in other experimental models are required to fully elucidate its suggested beneficial effects on mild chronic inflammatory conditions.

Keywords: lipogenesis, obesity, Ginkgo biloba extract, high fat diet, fatty acid synthase 


\section{INTRODUCTION}

The definition of white adipose tissue (WAT) as an inert mass for energy storage is long gone; over the last two decades the adipose tissue has been recognized as a dynamic tissue and key player in the modulation of energy metabolism $(1,2)$. Adipokines such as leptin, adiponectin, and tumour necrosis factor- $\alpha$ (TNF$\alpha$ ) have a direct effect on energy homeostasis and modulation of low-grade inflammation (3). The intake of high fat diets has the potential to not only disturb normal adipokine secretion but also to remodel adipose tissue by increasing adipocyte size and/or number, contributing to the development of a proinflammatory microenvironment $(4,5)$. These perturbations have been positively associated with metabolic disorders such as obesity, type 2 diabetes, non-alcoholic fatty liver disease (NAFLD), insulin resistance, and cardiovascular diseases $(6,7)$.

In obesity, particularly visceral obesity, enlarged WAT visceral adipocytes show dysregulated lipolysis, inducing high levels of circulating non-esterified fatty acids (NEFAs) $(8,9)$. NEFAs in normal circumstances are utilized as energy by tissues such as liver and muscle; however, when in excess they contribute to the development of insulin resistance (4, 9-11). Furthermore, in response to overnutrition, hypertrophic adipocytes contribute to increased circulating triacylglycerol (TAG) levels mainly from de novo lipogenesis, in which fatty acids (FA) are synthetized from non-lipid substrates, particularly carbohydrates, or from FA obtained from ex-situ lipid sources such as chylomicrons and very-low-density lipoproteins (VLDL) $(12,13)$. Visceral obesity seems to play a central role in the development of metabolic disorders, being associated with low-grade chronic inflammation and the production of pro-inflammatory cytokines which have the potential to trigger insulin resistance and endothelial dysfunction (14-16).

In this context, several pharmacological approaches have been tried for the treatment of obesity. However, more often than not such approaches were followed by undesired side effects, including psychiatric manifestations, increased risk of cardiovascular events, and others (17). Considering the dramatic increase in the prevalence of obesity over the last decades globally, a range of anti-obesogenic alternative supplementation therapies based on plant extracts (18) have been investigated.

More recently, Ginkgo biloba Extract (GbE) has been investigated as an alternative therapy for metabolic disorders associated with obesity. GbE, a herbal extract containing flavonoids, terpenoids, and terpene lactones (19), is a wellknown phytotherapic compound often employed as coadjuvant supplement in neurodegenerative diseases $(20,21)$, NAFLD $(22,23)$, type 1 and 2 diabetes $(24,25)$. Previous findings from our research group showed that diet-induced obese (DIO) rats supplemented with GbE showed reduced food and energy intake, reduced body adiposity, improved insulin signalling and sensitivity, enhanced insulin receptor and AKT phosphorylation, and reduced NFkB-p65 phosphorylation in retroperitoneal adipose tissue $(26,27)$.

GbE may have a potentially therapeutic use for menopauseassociated obesity; supplementation with $500 \mathrm{mg} / \mathrm{kg}$ of $\mathrm{GbE}$ stimulated hypothalamic serotonergic activity in ovariectomized rats (28). GbE isolated bioactive compounds have been demonstrated to stimulate lipolysis in 3T3-L1 adipocytes (29), and to inhibit adipogenesis through activation of the AMPK pathway (30). However, the effects of GbE supplementation on metabolic processes of visceral adipose tissue in DIO rats remain largely unknown. In view of the considerations highlighted above, the aim of the present study was to investigate the effects of GbE supplementation as a potentially anti-obesogenic effector for improvement in lipid metabolism of epididymal adipose tissue of DIO rats.

\section{MATERIALS AND METHODS \\ Ethical approval}

This study was carried out in strict accordance with the recommendations of the Guide for the Care and Use of Laboratory Animals. The Committee on Animal Research Ethics of the Universidade Federal de São Paulo approved all procedures for the care of the animals used in this study (Process number: 8700110814).

\section{Animal Care}

Two months-old male Wistar rats from Multidisciplinary Center for Biological Investigation in Laboratory Animals Science (CEMIB - Campinas, Brazil) were housed at 4 or 5 rats per cage and maintained in controlled lighting (12:12-h light/dark, lights on at 6:00 a.m. ) and temperature $\left(23^{\circ} \mathrm{C} \pm 1{ }^{\circ} \mathrm{C}\right)$ conditions, with ad libitum access to food and water.

Briefly, the high fat diet was prepared by mixing $40 \%$ (w/w) ground standard chow (Nuvilab ${ }^{\circledR}$, Brazil, $2.7 \mathrm{kcal} / \mathrm{g}$ ), with $28 \%(\mathrm{w} / \mathrm{w})$ melted lard, 20\% $(\mathrm{w} / \mathrm{w})$ casein powder, $10 \%(\mathrm{w} / \mathrm{w})$ sucrose, $2 \%(\mathrm{w} / \mathrm{w})$ soybean oil, and $0.02 \%(\mathrm{w} / \mathrm{w})$ butylated hydroxytoluene $(5.0 \mathrm{kcal} / \mathrm{g})$. All the ingredients were thoroughly mixed and lukewarm drinking water added to obtain the consistency necessary to allow perfect homogenization of the mixture and production of pellets, which were subsequently dried in a forced ventilation oven at $60^{\circ} \mathrm{C}$ for $24 \mathrm{~h}$. This diet provides $19.5 \%$ of energy from carbohydrate, $23.2 \%$ from protein, and $57.3 \%$ from fat, and has been demonstrated in previous studies to induce obesity $(26,27)$. The diet macronutrient composition was analysed in the laboratory of Bromatology and Microbiology of Foods, Universidade Federal de Sao Paulo, and the diet fatty acid composition was determined by gas chromatography (Table $\mathbf{1}$ ).

Over the course of 2 months for the development of obesity, normal fat diet-fed rats (NFD, $n=20$ ) received the standard chow, while the high fat diet-fed rats (HFD, $n=54$ ) received the lard enriched diet, as described above. All rats were weighted once weekly, and the food/energy intake was calculated by the difference between the food left from the food offered $24 \mathrm{~h}$ before. Food efficiency was calculated by the ratio of body weight gain $(\mathrm{g})$ to food ingestion $(\mathrm{g})$ weekly.

\section{GbE Supplementation}

At the end of the 2 months induction period, the HFD group was randomly sorted into two subsets. The NFD group and the first HFD subset received $1 \mathrm{~mL} 0.9 \%$ saline by gavage daily for 2 weeks, 
TABLE 1 | Macronutrients and fatty acid composition (\% of total fatty acids) of standard chow and high-fat diet.

\begin{tabular}{lcc}
\hline & Standard chow & High-fat diet \\
\hline Humidity (\%) & 9.1 & 1.1 \\
Lipids (\%) & 4.5 & 31.6 \\
Protein (\%) & 22.7 & 27.0 \\
Carbohydrates (\%) & 35.9 & 27.5 \\
Total fibre (\%) & 18.9 & 8.6 \\
Fixed mineral residue (\%) & 8.9 & 4.2 \\
Sodium chloride (\%) & 0.6 & 0.2 \\
Calculated energy (kcal/g) & 2.7 & 5.0 \\
Fatty acid composition (\% total) & & \\
SATURATED FATTY ACIDS & & 1.1 \\
Myristic acid - C14:0 & 0.0 & 21.4 \\
Palmitic acid - C16:0 & 14.6 & 11.6 \\
Stearic acid - C18:0 & 3.6 & \\
Monounsaturated fatty acid & & 1.7 \\
Palmitoleic acid - C16:1n7 & 0.0 & 21.4 \\
Vaccenic acid - C18:1n7 & 0.9 & 3.6 \\
Oleic acid - C18:1n9 & 24.1 & \\
Eicosanoic acid - C20:1n9 & 0.3 & \\
PoLYUNSATURATED FATTY ACIDS & & \\
Linoleic acid - C18:2n6 & 55.4 & \\
Linolenic acid - C18:3n3 & & \\
\hline & & \\
\hline
\end{tabular}

whilst the second HFD subset (HFD+GbE) was orally gavaged with GbE $500 \mathrm{mg} / \mathrm{kg}$, as previously described (31).

$\mathrm{GbE}$ was obtained from Huacheng Biotech Inc. (China), and the major bioactive compounds were flavone glycosides (25.21\%), terpenoids (6.62\%), ginkgolides A, B, C (3.09\%), and bilobalides $(2.73 \%)$. Food and energy intake were registered daily for the 2 weeks of supplementation. Body weight gain was calculated by the difference between the first and the last day of the 2 weeks period.

\section{Adipocyte Isolation}

Adipocyte isolation was performed as previously described and optimized (32-34). Briefly, epididymal fat pads were diced in small fragments in a flask containing $4 \mathrm{~mL}$ of DMEM supplemented with HEPES $(20 \mathrm{mM})$, glucose $(5 \mathrm{mM})$, bovine serum albumin (BSA, 1\%), and collagenase type II $(1 \mathrm{mg} / \mathrm{mL})$, $\mathrm{pH} 7.4$ and incubated for $\sim 40 \mathrm{~min}$ at $37^{\circ} \mathrm{C}$ in an orbital shaker. Isolated adipocytes were filtered through a plastic sieve $(150 \mu \mathrm{m})$ and washed three times in fresh buffer without collagenase. After washing and brief spin, the medium was thoroughly aspirated, and the adipocytes harvested. Adipocytes were photographed under an optic microscope ( $\times 100$ magnification) coupled to a microscope camera (AxioCam ERc5s; Zeiss ${ }^{\circledR}$, Oberkochen, Germany). Mean adipocyte volume $\left(4 / 3 \times \pi \times \mathrm{r}^{3}\right)$, expressed in $\mathrm{pL}$, was calculated by averaging the measurement of 50 cells, employing AxioVision LE64 software.

The percentage of adipocytes contained in the total cell suspension was determined using $40 \mu \mathrm{L}$ of the cell suspension in EHB buffer placed in glass capillary and subjected to centrifugation ( $500 \mathrm{~g}$ for $1 \mathrm{~min}$ ). The total volume of the suspension corresponds to $100 \%$ and the volume of adipocytes obtained after centrifugation gives the percentage of adipocytes of the sample.

\section{Lipolysis}

Lipolysis was estimated as concentration of glycerol release into the incubation medium. For this, isolated epididymal adipocytes $\left(1 \times 10^{6}\right.$ cells $\left./ \mathrm{mL}\right)$ were incubated in Krebs/Ringer/phosphate buffer ( $\mathrm{pH} 7.4)$ containing BSA $(20 \mathrm{mM})$ and glucose $(5 \mathrm{mM})$ for $30 \mathrm{~min}$ at $37^{\circ} \mathrm{C}$ in the presence or absence of isoproterenol $\left(2 \times 10^{-6} \mathrm{M}\right)$. The reaction was stopped by cooling the flasks on ice, and the media was carefully collected for measurement of glycerol release employing a free glycerol determination kit (Sigma $\left.{ }^{\circledR}\right)$. Results are expressed as nmol of glycerol / $1 \times$ $10^{6}$ adipocytes.

\section{Fatty Acid Uptake}

Fatty acid uptake, measured by intracellular accumulation of $\left[{ }^{3} \mathrm{H}\right]$-oleate, was quantified following previously established methods $(32,33)$. Briefly, isolated epididymal adipocytes $(1 \times$ $10^{6}$ cells/ mL) were incubated in Krebs/Ringer/phosphate buffer ( $\mathrm{pH} 7.4)$ containing BSA (1\%), glucose $(2 \mathrm{mM}),\left[{ }^{3} \mathrm{H}\right]$ - oleate $\left(100 \mu \mathrm{M}, 1850 \mathrm{~Bq} /\right.$ tube or well) for $2 \mathrm{~h}$ at $37^{\circ} \mathrm{C}$ in a water bath. At the end of the incubation period, the mixture was transferred to $1.5 \mathrm{~mL}$ tubes containing $400 \mu \mathrm{L}$ of silicone oil and centrifuged for $30 \mathrm{~s}$. The cell pellet on top of the oil layer was transferred to polypropylene tubes containing $2.5 \mathrm{~mL}$ of Dole's reagent for lipid extraction. After addition of $n$-heptane $(1.5 \mathrm{~mL})$ and distilled water $(1.5 \mathrm{~mL})$, tubes were vortexed and the mixture decanted for $5 \mathrm{~min}$. An aliquot of the upper phase was collected into a scintillation vial for the determination of radioactivity incorporated into TAG (1450 LSC, Couter MicroBeta, Trilux; Perkin Elmer, Waltham ${ }^{\circledR}$, MA, USA). Results are expressed as nmol of oleate $/ 1 \times 10^{6}$ cells $/ \mathrm{h}$.

\section{Incorporation of $\left[1-{ }^{14} \mathrm{C}\right]$-Acetate Into Triacylglycerol}

De novo lipogenesis in epididymal adipocytes was estimated by incubating isolated cells $\left(1 \times 10^{6}\right.$ cells $\left./ \mathrm{mL}\right)$ in Krebs/Ringer/phosphate buffer ( $\mathrm{pH}$ 7.4) containing BSA (1\%), glucose $(2 \mathrm{mM})$, and $\left[1-{ }^{14} \mathrm{C}\right]$-acetate $(1 \mathrm{mM}, 1850 \mathrm{~Bq} /$ tube or well) for $2 \mathrm{~h}$ at $37^{\circ} \mathrm{C}$ in a water bath and processed as described previously $(32,33)$. Results are expressed as nmol of acetate incorporated into TAG/ $1 \times 10^{6}$ cells $/ \mathrm{h}$.

\section{RNA Extraction and Quantitative Real-Time Polymerase Chain Reaction (qPCR)}

Total RNA from epididymal adipocytes was extracted with $\quad$ Trizol ${ }^{\circledR}$ reagent (Invitrogen Life Technologies ${ }^{\circledR}$ ) and reversely transcribed into cDNA using a HighCapacity cDNA kit (Applied Biosystems ${ }^{\circledR}$ ) following the manufacturer's instructions. Gene expression was evaluated by real-time qPCR using a Rotor Gene (Qiagen ${ }^{\circledR}$ ) and SYBR Green as fluorescent dye with Beta2M as housekeeping gene.

Primers used and annealing temperatures were employed as followed: FAS (Fasn) $\left(5^{\prime}-3^{\prime}\right.$ sense: GAGTCCGAGTCT 
GTCTCCCGCTTGA; $5^{\prime}-3^{\prime}$ antisense: GCCGTGAGGTTGCTG TTGTCTGTAG; $64^{\circ} \mathrm{C}$; NM_017332); HSL-(Lipe) (5'-3' sense: CCTGCTGACCATCAACCGAC; $5^{\prime}-3^{\prime}$ antisense: CCTCGATCT CCGTGATATTCCAGA; $60^{\circ}$ C; NM_012859); Perilipin 1 (Plin1) (5'-3' sense: CCTCTTGCCCCGATCTGGAT; $5^{\prime}-3^{\prime}$ antisense: CAAGCCCCAAGGATGCCTTA; $60^{\circ} \mathrm{C}$; NM_013094); beta-2 microglobulin (Beta2M) $\left(5^{\prime}-3^{\prime}\right.$ sense: CTC AGT TCC ACC CAC CTC AG; $5^{\prime}-3^{\prime}$ antisense: GCA AGC ATA TAC ATC GGT CTC G; 56०C; NM_012512). The $2^{-\Delta \Delta C t}$ method (35) was used to evaluate the relative quantification of amplification products relative to the control group NFD. At least one sample from each group was included in each run, and reactions were carried out in triplicate.

\section{Protein Expression Estimation by Western Blotting}

Epididymal fat pads were removed and immediately homogenized in $1 \mathrm{~mL}$ lysis buffer $(100 \mathrm{mM}$ Tris, $\mathrm{pH}$ 7.5, $10 \mathrm{mM}$ EDTA, $0.1 \mathrm{mg} / \mathrm{mL}$ aprotinin; $2 \mathrm{mM}$ PMSF; $10 \mathrm{mM}$ sodium orthovanadate; $100 \mathrm{mM}$ sodium fluoride; $10 \mathrm{mM}$ sodium pyrophosphate; and 10\% TritonX-100), homogenized and centrifuged at $16,000 \mathrm{~g}$ for $40 \mathrm{~min}$ at $4^{\circ} \mathrm{C}$.

Fifty micrograms of protein were separated in 10\% SDSPAGE, transferred onto nitrocellulose membranes and incubated with primary antibody anti-Fatty Acid Synthase (FAS Santa Cruz ${ }^{\circledR}$ - SC20140), anti-phospho-hormone-sensitive lipase (p-HSL Cell Signaling ${ }^{\circledR}$ - \#4139) and anti-hormonesensitive lipase (HSL Cell Signaling ${ }^{\circledR}$ - \#4107). Membranes were subsequently incubated with peroxidase-conjugated antibody (Cell Signaling ${ }^{\circledR}$ _ \#7074) followed by chemiluminescence detection. $\beta$-tubulin (Cell Signaling ${ }^{\circledR}$ - \#2146) levels were used as internal standard. Quantitative analysis was performed with ImageJ software (Image $)^{\circledR}$, version 2.0, Maryland, USA). In all experiments, at least one sample from each group was analysed simultaneously and the results were expressed as percentage change relative to NFD group levels, as described previously (27). Representative pictures of Western blotting gels are provided in the Supplementary Data Sheet 1.

\section{Statistical Analysis}

Data were subjected to quality tests such as Shapiro-Wilk (normality) and/or Levenne (homogeneity). If necessary, data were standardized according to the log transformation. Descriptive analysis was performed using mean \pm SEM, and measurements were taken from distinct samples. Comparisons of body mass, food intake, body weight gain, and food efficiency between NFD and HFD were assessed by Student's t-test for independent samples. One-way ANOVA followed by Tukey posthoc test was employed to assess the effects of supplementation among NFD, HFD, and HFD+GbE. Mann-Whitney test was performed to analyse acetate incorporation into lipids, since this was a non-linear parameter compared between HFD and HFD+GbE groups only. Statistical analysis was performed using SPSS ${ }^{\circledR}$ software version 20 . The number of samples used in each experiment is shown in the respective Results section. The level of significance adopted was set at $p \leq 0.05$.

\section{RESULTS}

\section{Food, Energy Intake, and Body Weight Gain During the Obesity Induction Period}

Food intake $(\mathrm{g} / 100 \mathrm{~g} / 24 \mathrm{~h})$ was $\sim 23 \%$ higher $(p<0.001)$ in the HFD group in the first week of feeding (Figure 1A). From the third week onwards, HFD rats ingested $\sim 29 \%$ ( $p=0.001)$ less food in grams, but their energy intake ( $\mathrm{kcal} / 100 \mathrm{~g} / 24 \mathrm{~h})$ remained $\sim 44 \%(p=0.001)$ higher than NFD in the same period (Figure 1B). Additionally, food efficiency [BW gain (g) / food ingestion (g)] was significantly higher in HFD $(10.64 \pm 0.37)$ than in NFD $(5.09 \pm 0.21)$ $(p<0.001)$ (Figure 1C).

Throughout the 2 months of obesity-induction period, both groups showed continued body weight increase. From weeks 2 to 9 , the HFD group gained around $16 \%(p<0.001)$ more weight than the NFD group (Figure 2A). The high-fat diet intake resulted in an extra $153.3 \mathrm{~g}$ of body weight gain in relation to the chow-fed rats $(p<0.001)$ (Figure 2B).

\section{Food, Energy Intake, and Body Weight Gain During the GbE Supplementation Period}

At the end of the 2 months obesity-induction period (NFD vs. HFD), the HFD group was randomly sorted into two subsets: HFD $(n=24)$ or HFD+GbE $(n=27)$. For the two following weeks, both HFD and HFD+GbE groups showed reduced food intake in comparison to NFD (45.1 and 50.1\%, respectively; $p<0.001$ ), but the HFD $+\mathrm{GbE}$ group showed reduced food intake in comparison to $\operatorname{HFD}(8.9 \%, p=0.014)$. The energy intake was statistically similar between NFD and HFD; however, the HFD+GbE energy intake was significantly lower than NFD $(8.7 \%, p=0.001)$ and HFD $(8.9 \%, p<0.001)$ (Figures 3A,B). Body weight gain (g) and food efficiency [BW gain (g)/ food ingestion $(\mathrm{g})$ ] during the 2 weeks supplementation period were monitored; however, no statistically significant differences were found (Figures 4A,B).

\section{Adipocyte Volume and Metabolism}

Adipocyte volume was significantly larger in HFD than NFD $(114 \%, p=0.01)$, but GbE supplementation reduced this parameter by $42.5 \%$, as compared to HFD $(p=0.03)$. Adipocyte volume was statistically similar between $\mathrm{HFD}+\mathrm{GbE}$ and NFD (Figures 5A,B).

No statistically significant differences were found in lipolysis rate $\left(\mathrm{nmol} / 10^{6}\right.$ cells $)$ or isoproterenol-induced lipolysis rate (Figures 5C,D) amongst the three groups. However, oleate incorporation into lipids was $130 \%$ higher $(p=0.01)$ in HFD $\left(39573.1 \mathrm{nmol} / 10^{6}\right.$ cells) than NFD $\left(17189.9 \mathrm{nmol} / 10^{6}\right.$ cells $)$. Additionally, GbE supplementation showed a strong tendency to reduce this parameter by $43 \%(p=0.06)\left(22412.7 \mathrm{nmol} / 10^{6}\right.$ cells $)$ in relation to HFD (Figure 5E). Acetate incorporation into lipids ( $\mathrm{nmol} / 10^{6}$ cells) was reduced by $115 \%(p=0.003)$ in HFD+GbE $\left(19286.5 \mathrm{nmol} / 10^{6}\right.$ cells $)$ in relation to HFD $\left(41560.2 \mathrm{nmol} / 10^{6}\right.$ cells) (Figure 5F). 
A
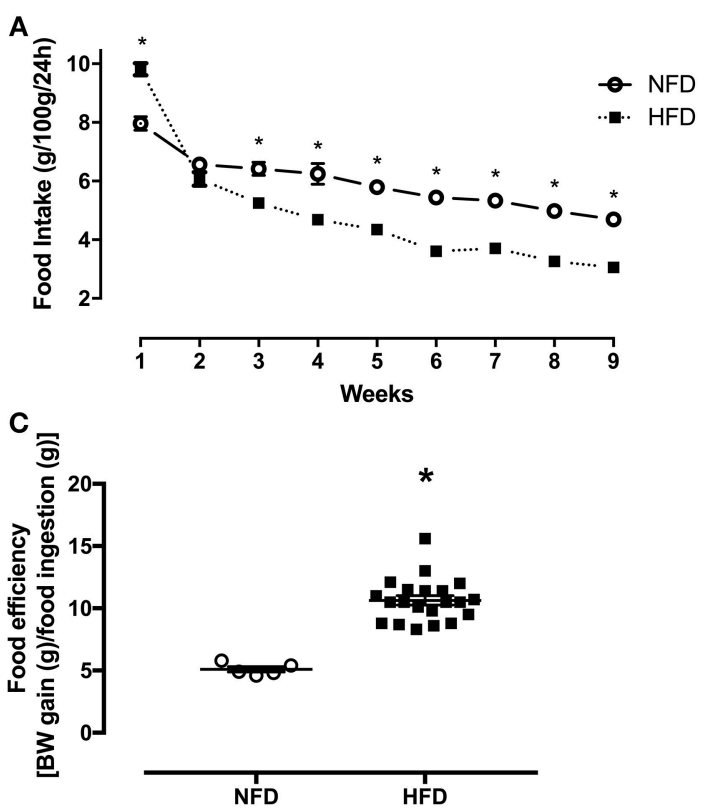

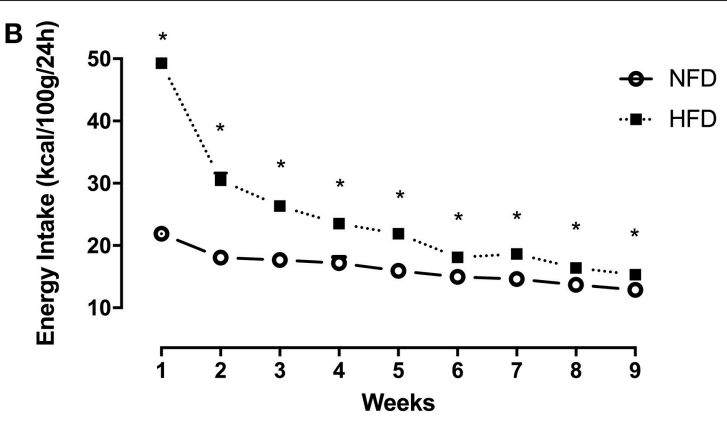

FIGURE 1 | Food intake, energy intake, and food efficiency. Food intake (g/100 g/24 h) (A), energy intake (kcal/100 g/24 h) (B), and food efficiency [BW gain (g)/food ingestion(g)] (C) of normal-fat diet (NFD; $n=5$ ) and high-fat diet (HFD; $n=13$ ) groups during the obesity induction period. ${ }^{*} p<0.05$ vs. NFD (Student's $t$-test).
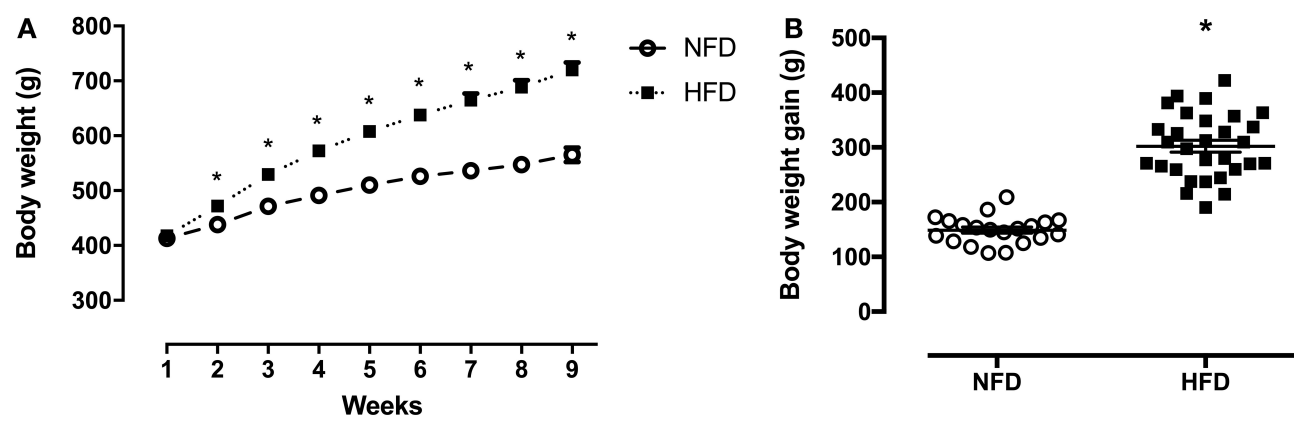

FIGURE 2 | Body composition. Body weight (g) during the obesity induction period (A) and body weight gain (difference between initial and final BW) (g) (B) of normal-fat diet (NFD; $n=20$ ) and high-fat diet (HFD; $n=29){ }^{*} p<0.05$ vs. NFD (Student's $t$-test).
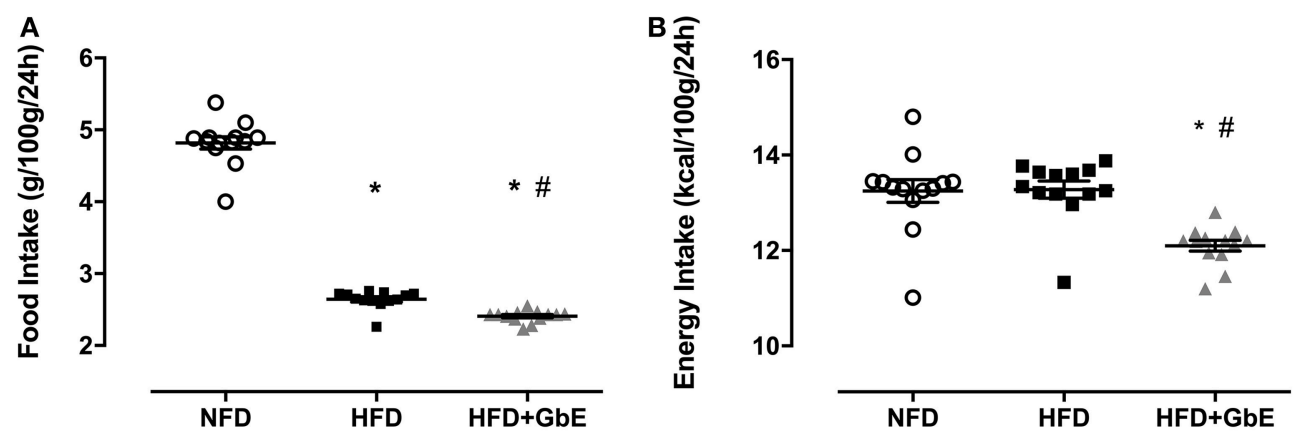

FIGURE 3 | Accumulated food and energy intake after supplementation. Accumulated food intake (g/100 g/24 h) (A) and energy intake (kcal/100 g/24 h) (B) of normal-fat diet (NFD; $n=10)$, high-fat diet (HFD; $n=24)$ and high-fat diet plus GbE supplementation (HFD+GbE; $n=24) .{ }^{*} p<0.05$ vs. NFD and \#p $<0.05$ vs. HFD (One-way ANOVA). 

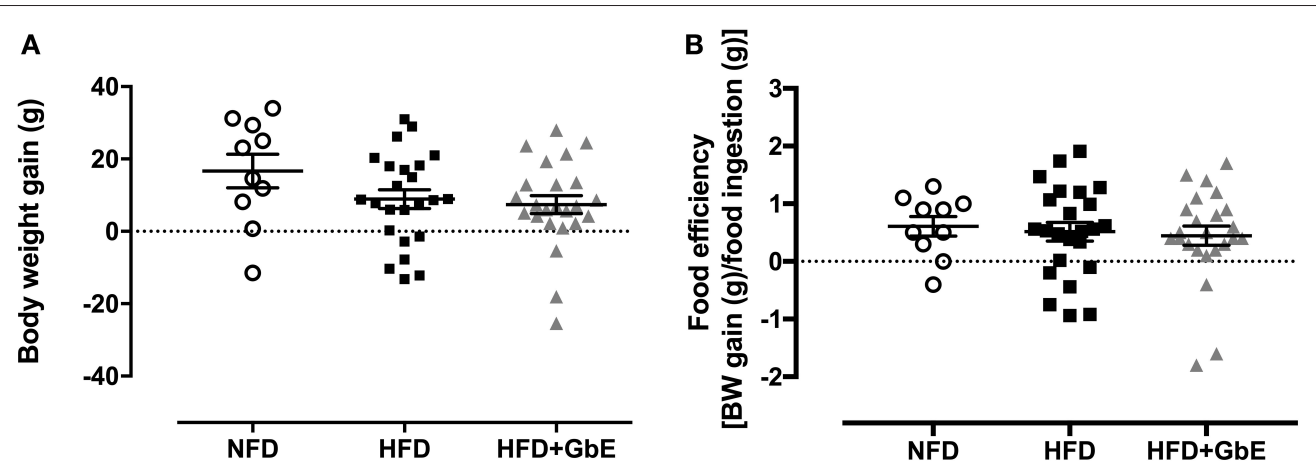

FIGURE 4 | Body composition after supplementation. Body weight gain (g) (A) and food efficiency [BW gain (g)/food ingestion(g)] (B) of normal-fat diet (NFD; $n=10)$, high-fat diet (HFD; $n=24$ ) and high-fat diet plus GbE supplementation (HFD+GbE; $n=24) .{ }^{*} p<0.05$ vs. NFD (One-way ANOVA).

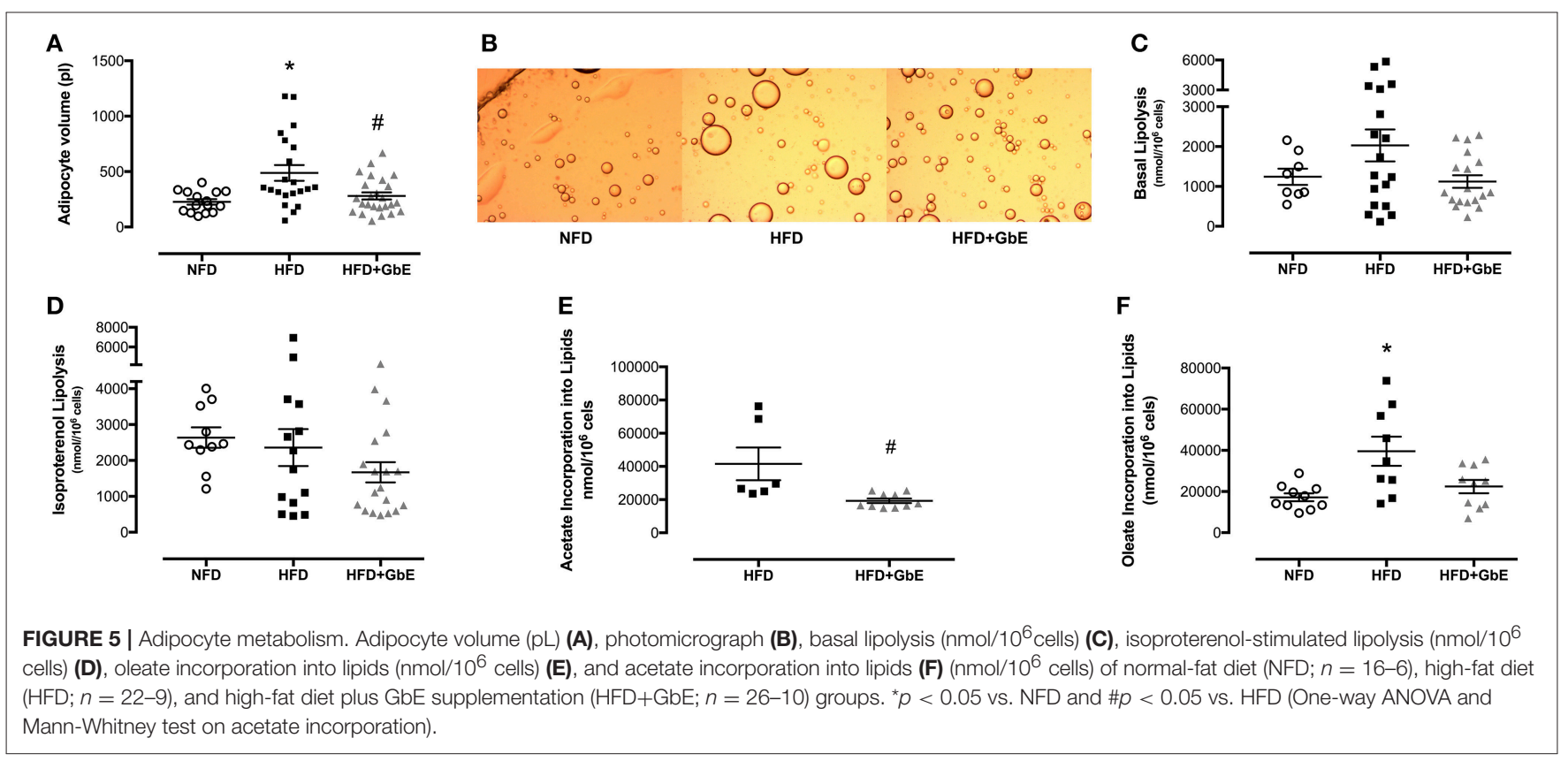

\section{Epididymal Adipose Tissue mRNA Expression and Protein Synthesis}

PLIN-1 (perilipin 1), FASN (fatty acid synthase), and HSL (hormone-sensitive lipase) epididymal adipose tissue mRNA expression were quantified by real time PCR. PLIN 1 gene expression (Figure 6A) was increased by $335 \%(p=0.06)$ in HFD in comparison to NFD but decreased by $95.2 \%$ in $\mathrm{HFD}+\mathrm{GbE}$ $(p=0.01)$ in comparison to HFD.

No statistically significant differences were found in FASN gene expression between HFD and NFD, but GbE supplementation significantly decreased it by $70.7 \%$ in relation to NFD (Figure 6B, $p=0.03$ ). The FASN gene expression experiment was followed by tissue FAS protein quantification by western blotting. We have confirmed that there were no differences in FAS protein between NFD and HFD, but GbE supplementation did reduce tissue FAS content by $38 \%$ $(p=0.05)$ in relation to NFD (Figure 7A). No statistically significant differences were found in p-HSL and HSL protein amongst the three groups (Figures 7B-D).

\section{DISCUSSION}

GbE is the most widely herbal supplement therapy used worldwide (36). Its effects have been investigated in a range of chronic diseases including NAFLD (22, 23), Alzheimer's disease (37), memory loss (31), and cancer (38). Recent investigations from our research group have identified some of the molecular effects of GbE supplementation in obese rats. We have previously showed that GbE supplementation significantly reduced appetite and significantly stimulated hypothalamic serotonergic activity in obesity-associated ovariectomized rats (28). Additionally, diet-induced obese rats showed significant improvement in insulin sensitivity and increased insulin receptor (IR) and AKT phosphorylation after GbE supplementation (27). 


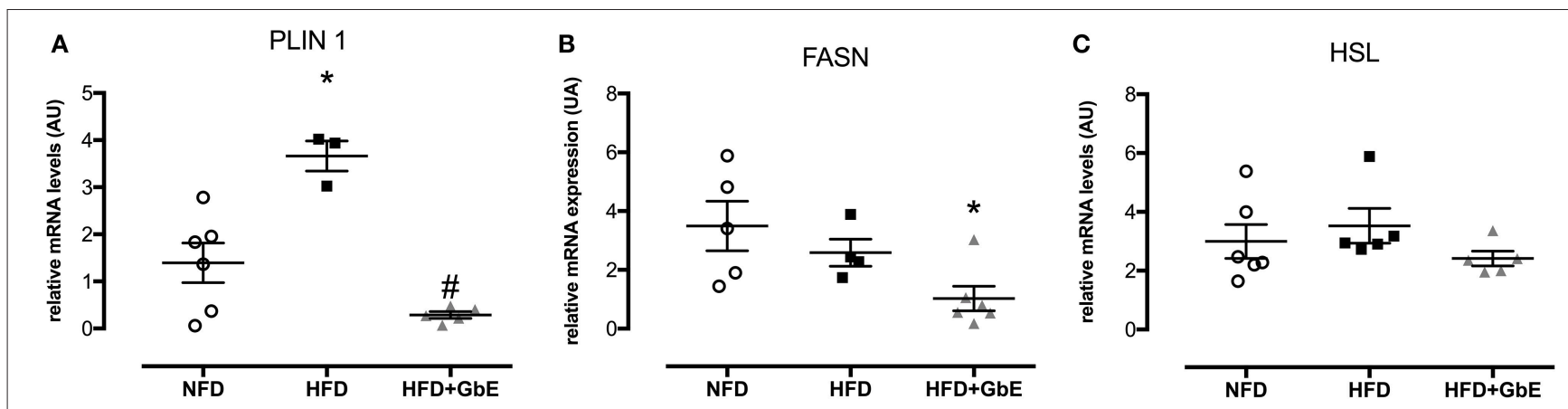

FIGURE 6 | Gene expression. Effect of GbE supplementation on epididymal adipose tissue gene expression of PLIN1 (A), FASN (B), and HSL (C), normal-fat diet (NFD; $n=6-4$ ), high-fat diet (HFD; $n=5-3$ ), and high-fat diet plus GbE supplementation (HFD+GbE; $n=6-4)$ groups. ${ }^{*} p<0.05$ vs. NFD and \#p $<0.05$ vs. HFD (One-way ANOVA). Gene expression in epididymal WAT depot was evaluated by Real Time PCR.

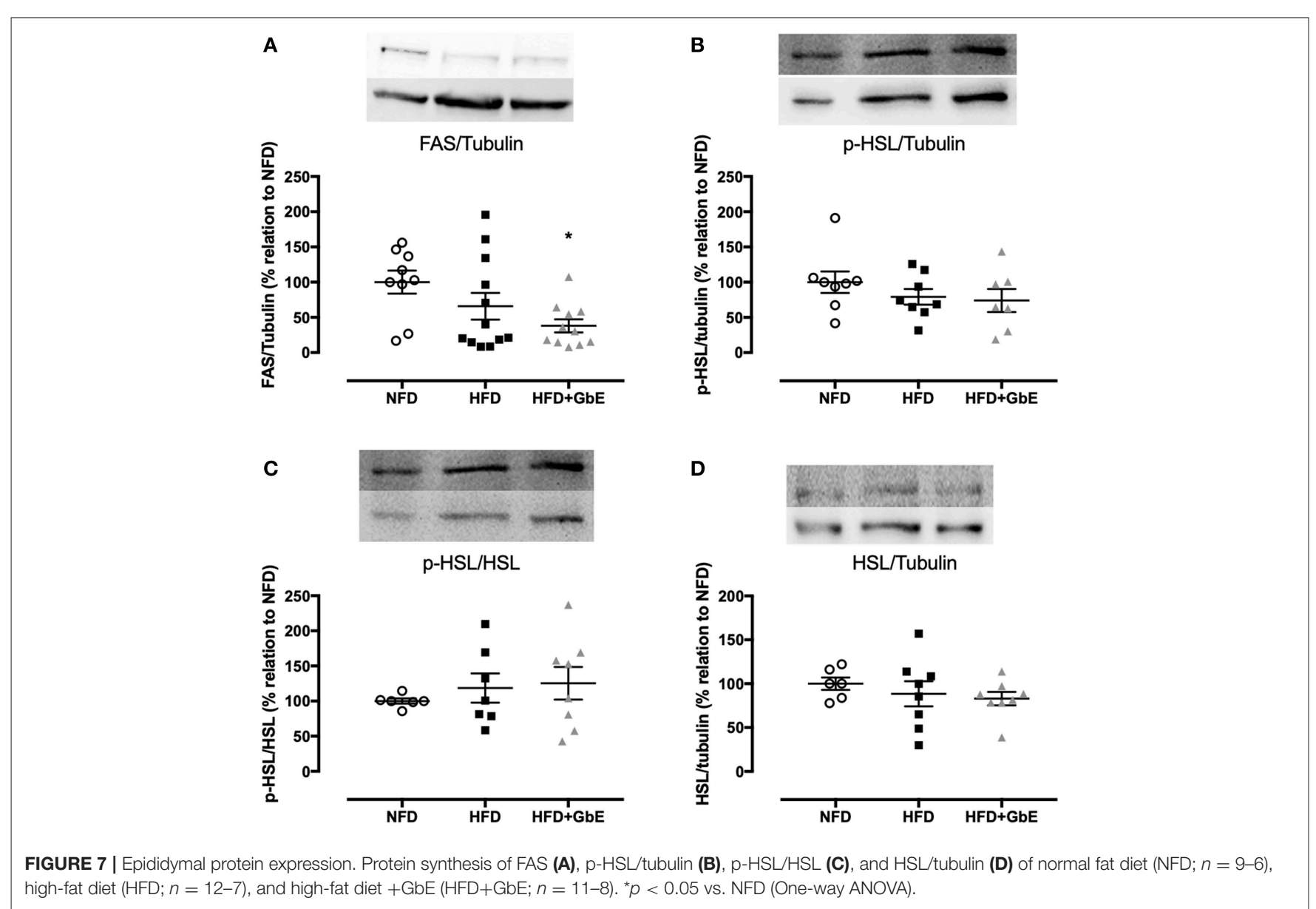

Collectively, these results suggest a potentially beneficial effect of $\mathrm{GbE}$ as coadjuvant for the treatment of obesity. In order to further test this hypothesis, in the current investigation we examined other markers of lipid metabolism on epididymal white adipose tissue of diet-induced obese rats supplemented with GbE.

In the present study, we observed a lower food intake (g/100 $\mathrm{g} / 24 \mathrm{~h}$ ) but higher relative energy intake ( $\mathrm{kcal} / 100 \mathrm{~g} / 24 \mathrm{~h}$ ) in HFD-fed rats throughout the 2 months of obesity-induction period, prior to GbE intervention. The HFD was effective in inducing obesity; HFD-fed rats showed significantly increased body weight in comparison to NFD-fed rats, as well as increased masses of retroperitoneal and epididymal adipose tissue. Such findings have been described previously, and it is well-known that lard-based high-fat diets increase body weight and visceral fat accumulation $(26,39,40)$.

Further metabolic manifestations have been observed in lardfed obese Wistar rats. Dornellas et al. (41) showed that the 
intake of lard-enriched high fat diet for 8 weeks resulted in significantly decreased linoleic acid, alpha-linolenic acid and the respective elongated desaturated omega 6 and 3 PUFAs in liver, serum, retroperitoneal, epididymal and mesenteric white adipose tissue lipid extracts. Due to the similarities between the experimental model used in our study and the one employed by Dornellas et al., it is reasonable to suggest that the content of essential fatty acids was decreased in our HFD rats, which may help to explain the phenotypic disturbances found in these animals.

We found at the end of the 2 weeks GbE supplementation period reduced food intake and reduced relative energy intake in GbE supplemented rats, in comparison to the non-supplemented obese ones. Similar results were observed in previous studies from our research group $(26,27)$. It has been proposed that Ginkgo biloba may stimulate serotoninergic systems, inducing hypophagia (28).

The reduced energy intake observed in HFD+GbE did not lead to significantly reduced body weight gain; both HFD and HFD+GbE showed statistically similar body weight at the end of the 2-week supplementation period. However, we have previously demonstrated that GbE induced a significant reduction in the mass of retroperitoneal and epididymal fat pads of obese rats (26). Furthermore, epididymal adipocytes harvested from HFD rats were significantly larger than those harvested from NFD rats, but the present data also showed that GbE supplementation induced a reduction in adipocyte volume of obese rats, bringing this index down to a volume similar to the NFD group.

This is, in our opinion, a remarkable effect of GbE supplementation. Adipocyte hypertrophy is a classical manifestation of obesity and is directly associated with the aetiology of macrophage infiltration, hypoxia, secretion of pro-inflammatory cytokines (e.g., TNF- $\alpha$, IL-6, IL-1 $\beta$ ) and reduced production of adiponectin. Such disturbances induce low grade inflammation and insulin resistance $(11,42)$. Not only that, abnormally expanded adipocytes have a reduced capacity to further store additional amounts of triacylglycerol, leading to its ectopic deposition in other organs such as skeletal muscle, heart, pancreas, and liver $(3,43)$. A reduction of adipocyte volume without concomitant losses in body weight, which we did find in the present study, could well possibly suggest an improvement in body composition. Further studies are however needed to further investigate this hypothesis.

The reduced adipocyte volume observed in the $\mathrm{HFD}+\mathrm{GbE}$ rats may be associated with their lowered food intake; however, we do not believe these findings suggest starvation. Calorie restriction has been associated with starvation signals such as reduced leptin and insulin (44), but in the opposite direction, we have previously found increased insulin levels and activity in obese rats supplemented with GbE submitted to the same experimental protocol (26).

Increased visceral adiposity and perturbations in adipocyte volume are only a few of the manifestations seen in adipose tissue in obesity; lipid uptake and lipolysis rate are also disturbed (45). In the present study, the lipolysis index was quantified by the amount of glycerol released from incubated adipocytes into the incubation medium. Isoproterenol, a sympathomimetic compound, was added to mimic adrenergic activation upon lipolysis. We found no statistically significant differences in either basal or isoproterenol-stimulated lipolysis amongst the three groups investigated. It is known however that lipolysis rate is higher in obesity (46). Corroborating this observation, in the current investigation, despite the absence of statistically significant differences in lipolysis rate amongst the three groups, HFD+GbE adipocytes showed basal lipolysis rate $\sim 45 \%$ lower, and isoproterenol-stimulated lipolysis $\sim 15 \%$ lower than HFD adipocytes.

We also quantified in ex-vivo epididymal adipocytes the fatty acid incorporation into TAG, defined as intracellular accumulation of $\left[3^{\mathrm{H}}\right]$-oleate. Our results show that incorporation was significantly higher in HFD in comparison to NFD (Figure 5E), and GbE reduced it by $43 \%$ in relation to HFD (Figure 5E).

In the present investigation, lipolysis rate remained statistically similar between HFD and NFD. Furthermore, oleate incorporation was significantly higher in HFD. Taken these results together, it is expected that in the longer term HFD adipocytes would only expand their volumes further, deteriorating the molecular consequences of obesity. However, our results suggest that GbE would be effective in impairing such deterioration, as lipolysis rate and fatty acid incorporation were lower in the rats that received it as compared to the ones that did not. Both biomarkers were also statistically similar between $\mathrm{HFD}+\mathrm{GbE}$ and NFD. Our hypothesis is further corroborated by the findings of intracellular incorporation of $\left[1-{ }^{14} \mathrm{C}\right]$-acetate, presented in Figure 6E. Acetate is a key component in fatty acid synthesis, and we found significantly reduced acetate incorporation into lipids in the $\mathrm{HFD}+\mathrm{GbE}$ group in relation to HFD.

Ginkgo biloba extract is a rich mixture of polyphenolic compounds, including ginkgolides, bilobalides, quercetin, and several others (47). Previous studies showed that 3T3-L1 adipocytes incubated with ginkgolide $\mathrm{C}$ showed increased ATGL and HSL activity and AMPK phosphorylation, as well as decreased activity of acetyl-CoA carboxylase for fatty acid synthesis (30). Furthermore, 3T3-L1 cells subjected to hypoxia and incubated with bilobalide showed reduced pro-inflammatory biomarkers and improved insulin sensitivity (48). Similarly, ginkgetin, a biflavone from Ginkgo biloba, has been described as a STAT5 inhibitor, blocking the differentiation of pre-adipocytes into adipocytes harvested from high-fat diet-induced obese mice (49). Moreover, OP9 cells, which differentiate into adipocytes in vitro, showed reduced adipogenesis, increased HSL and decreased FAS expression upon treatment with quercetin (50). Such results confirm previously published findings that 3T3-L1 adipocytes treated with a range of biflavones found in Ginkgo biloba showed increased lipolysis rate (29), and that biflavones inhibit cAMP-phosphodiesterase in rat adipose tissue (51).

Perilipin 1 is an intracellular protein that covers the lipid droplet surface in adipocytes, regulating TAG storage and mediating stimulated lipolysis (13). Higher perilipin activity (52) and higher TNF- $\alpha$ levels (53) are observed in obesity. TNF$\alpha$ induces lipolysis mediated by the activation of perilipin 1 , promoting its displacement from the lipid droplet, making the TAG molecule more accessible to HSL (43). 
In the present investigation, we found lower perilipin 1 relative mRNA levels in $\mathrm{HFD}+\mathrm{GbE}$ as compared to HFD, down to levels similar to the NFD group. The lower perilipin levels found in GbE-supplemented rats may suggest that a lower lipolysis rate will occur in the longer term, further corroborating the lipolysis findings described above. Also, it further supports the hypothesis that GbE supplementation may lead to lower fat accumulation in the long term.

Fatty Acid Synthase (FAS) is another pivotal protein in the regulation of body adiposity, utilizing malonyl-CoA and acetylCoA for the synthesis and elongation of fatty acid chains, which are eventually incorporated into lipid droplets (13). Higher levels of Fasn mRNA and FAS protein have been described in obesity, in visceral fat accumulation, and in enlarged insulin-resistant adipocytes (54-56). In the present study, we found decreased Fasn mRNA gene expression and FAS protein synthesis in the $\mathrm{HFD}+\mathrm{GbE}$ group in comparison to the NFD group, which suggests GbE could have a FAS-inhibiting effect.

FAS has been proposed as a potential therapeutic target for the treatment of obesity $(54,57)$, and grape skin extract and resveratrol have shown FAS enzyme-inhibiting properties. In 3T3-L1 pre-adipocytes, resveratrol reduced lipid accumulation (58). Furthermore, resveratrol treatment decreased the epididymal adipose tissue Fasn mRNA expression in high fat diet-fed mice (59). FAS inhibition is followed by malonyl-CoA, acetyl-CoA and NADPH accumulation, which is interpreted by the cell as a signal for abundance of energy (58).

Moreover, FAS may be an important modulator of feeding regulation. C75 is a synthetic inhibitor of FAS found to suppress food intake in obese mice mediated by NPY/AgRP orexigenic neurons, also increasing the expression of MelaninConcentrating Hormone and its receptor in the hypothalamus. C75 reduced body weight and body fat content, and normalized obesity-associated hyperglycaemia and hyperinsulinemia $(55,57$, 60 ). In the present study, we observed lower food and calorie intake in the HFD+GbE rats, which may be associated with decreased levels of FAS gene expression and protein synthesis.

In summary, our study shows that rats fed a high fat diet for 2 months and subsequently supplemented with GbE for 2 weeks showed significant reduction in several biomarkers of lipid metabolism, including reduced epididymal adipocyte volume and $\left[1-{ }^{14} \mathrm{C}\right]$-acetate incorporation into fatty acids, Plin $1 \mathrm{mRNA}$, Fasn mRNA, and protein levels, alongside a tendency for reduced epididymal $\left[{ }^{3} \mathrm{H}\right]$-oleate incorporation. Furthermore, the energy intake of GbE-supplemented rats was significantly lower than of rats receiving a control diet and of rats received the high fat diet only.

These findings allow us to suggest that GbE supplementation might be a promising alternative anti-obesogenic therapeutic approach. This is of particular relevance for obese patients who

\section{REFERENCES}

1. Fantuzzi G. Adipose tissue, adipokines, and inflammation. J Allergy Clin Immunol. (2005) 115:911-20. doi: 10.1016/j.jaci.2005. 02.023 do not successfully engage in nutritional and positive lifestyle reeducation programmes. However, due to the limitations of this study, as it involves a rodent model, further studies are necessary to test the validity of our hypothesis.

\section{ETHICS STATEMENT}

This study was carried out in strict accordance with the recommendations of the Guide for the Care and Use of Laboratory Animals. The Committee on Animal Research Ethics of the Universidade Federal de São Paulo approved all procedures for the care of the animals used in this study (Process number: 8700110814).

\section{AUTHOR CONTRIBUTIONS}

$\mathrm{BH}$ contributed to conception and design of the work, acquisition, analysis and interpretation of data for the work, drafted and revised the manuscript and provided final approval of the submitted version, responsible for all study aspects including its accuracy and integrity. MC, RdS, TF, and MM contributed to the data acquisition, analysis and interpretation, revised the manuscript and provided final approval of the submitted version, responsible for all study aspects including its accuracy and integrity. $\mathrm{AB}$ contributed to the data analysis and interpretation; drafted and revised the manuscript, revised the manuscript and provided final approval of the submitted version, responsible for all study aspects including its accuracy and integrity. MA-V and MT contributed to conception and design of the work, analysis and interpretation of data for the work, drafted and revised the manuscript and provided final approval of the submitted version, responsible for all study aspects including its accuracy and integrity. All authors approved the final version of the manuscript.

\section{ACKNOWLEDGMENTS}

This research was supported by grants from the Brazilian agencies: Coordenação de Aperfeiçoamento de Pessoal de Nível Superior - Brazil (CAPES) - Finance Code 001 and PDSE 19/2016 - grant number 88881.133658/2016-01 and by the Fundação de Amparo à Pesquisa do Estado de São Paulo (FAPESP, Brazil, grant number 2014/18929-9). The authors are also grateful for the University of Worcester for partial financial support.

\section{SUPPLEMENTARY MATERIAL}

The Supplementary Material for this article can be found online at: https://www.frontiersin.org/articles/10.3389/fendo. 2019.00284/full\#supplementary-material

2. Zhang $\mathrm{H}$, Zhang C. Adipose talks to distant organs to regulate insulin sensitivity and vascular function. Obesity. (2010) 18:2071-6. doi: 10.1038/oby. 2010.91

3. Vázquez-Vela MEF, Torres N, Tovar AR. White adipose tissue as endocrine organ and its role in obesity. Arch 
Med Res. (2008) 39:715-28. doi: 10.1016/j.arcmed.2008. 09.005

4. Choe SS, Huh JY, Hwang IJ, Kim JBJI, Kim JBJI. Adipose tissue remodeling: Its role in energy metabolism and metabolic disorders. Front Endocrinol. (2016) 7:30. doi: 10.3389/fendo.2016.00030

5. Corbett SW, Stern JS, Keesey RE. Energy expenditure in rats with diet-induced obesity. Am J Clin Nutr. (1986) 44:173-80.

6. Ruan $\mathrm{H}$, Dong LQ. Adiponectin signaling and function in insulin target tissues. J Mol Cell Biol. (2016) 8:101-9. doi: 10.1093/jmcb/mjw014

7. Sáinz N, Barrenetxe J, Moreno-Aliaga MJ, Martínez JA. Leptin resistance and diet-induced obesity: central and peripheral actions of leptin. Metabolism. (2015) 64:35-46. doi: 10.1016/j.metabol.2014.10.015

8. Stich V, Berlan M. Physiological regulation of NEFA availability: lipolysis pathway. Proc Nutr Soc. (2004) 63:369-74. doi: 10.1079/PNS20 04350

9. Wueest S, Rapold RA, Rytka JM, Schoenle EJ, Konrad D. Basal lipolysis, not the degree of insulin resistance, differentiates large from small isolated adipocytes in high-fat fed mice. Diabetologia. (2009) 52:541-6. doi: 10.1007/s00125-008-1223-5

10. Frühbeck G, Méndez-Giménez L, Fernández-Formoso J-A, Fernández S, Rodríguez A. Regulation of adipocyte lipolysis. Nutr Res Rev. (2014) 27:63-93. doi: 10.1017/S095442241400002X

11. Rutkowski JM, Stern JH, Scherer PE. The cell biology of fat expansion. J Cell Biol. (2015) 208:501-12. doi: 10.1083/jcb.201409063

12. Lafontan $M$, Langin D. Lipolysis and lipid mobilization in human adipose tissue. Prog Lipid Res. (2009) 48:275-97. doi: 10.1016/j.plipres.2009. 05.001

13. Proença ARG, Sertié RAL, Oliveira AC, Campaña $A B$, Caminhotto RO, Chimin P, et al. New concepts in white adipose tissue physiology. Braz J Med Biol Res. (2014) 47:192-205. doi: 10.1590/1414-431X20132911

14. McLaughlin T, Lamendola C, Liu A, Abbasi F. Preferential fat deposition in subcutaneous versus visceral depots is associated with insulin sensitivity. J Clin Endocrinol Metab. (2011) 96:E1756-60. doi: 10.1210/jc.2011-0615

15. Monteiro R, Azevedo I. Chronic inflammation in obesity and the metabolic syndrome. Mediators Inflamm. (2010) 2010:289645. doi: 10.1155/2010/289645

16. Yamashita AS, Lira FS, Rosa JC, Paulino EC, Brum PC, Negrão CE, et al. Depot-specific modulation of adipokine levels in rat adipose tissue by dietinduced obesity: the effect of aerobic training and energy restriction. Cytokine. (2010) 52:168-74. doi: 10.1016/j.cyto.2010.07.006

17. Martin KA, Mani MV, Mani A. New targets to treat obesity and the metabolic syndrome. Eur J Pharmacol. (2015) 763:64-74. doi: 10.1016/j.ejphar.2015.03.093

18. de Freitas Junior LM, de Almeida EB Jr. Medicinal plants for the treatment of obesity: ethnopharmacological approach and chemical and biological studies. Am J Transl Res. (2017) 9:2050-64.

19. Singh B, Kaur P, Gopichand, Singh RD, Ahuja PS. Biology and chemistry of Ginkgo biloba. Fitoterapia. (2008) 79:401-18. doi: 10.1016/j.fitote.2008.05.007

20. Birks J, Grimley Evans J. Ginkgo biloba for cognitive impairment and dementia. Cochrane Database Syst. Rev. (2009) CD003120. doi: 10.1002/14651858.CD003120.pub3

21. Zhang H-F, Huang L-B, Zhong Y-B, Zhou Q-H, Wang H-L, Zheng G-Q, et al. An overview of systematic reviews of Ginkgo biloba extracts for mild cognitive impairment and dementia. Front Aging Neurosci. (2016) 8:276. doi: 10.3389/fnagi.2016.00276

22. Wang SD, Xie ZQ, Chen J, Wang K, Wei T, Zhao AH, et al. Inhibitory effect of Ginkgo biloba extract on fatty liver: regulation of carnitine palmitoyltransferase 1a and fatty acid metabolism. J Dig Dis. (2012) 13:525-35. doi: $10.1111 / j .1751-2980.2012 .00627 . x$

23. Yan Z, Fan R, Yin S, Zhao X, Liu J, Li L, et al. Protective effects of Ginkgo biloba leaf polysaccharide on nonalcoholic fatty liver disease and its mechanisms. Int J Biol Macromol. (2015) 80:573-80. doi: 10.1016/j.ijbiomac.2015.05.054

24. Kudolo GB, Wang W, Javors M, Blodgett J. The effect of the ingestion of Ginkgo biloba extract (EGb 761) on the pharmacokinetics of metformin in non-diabetic and type 2 diabetic subjects-a double blind placebo-controlled, crossover study. Clin Nutr. (2006) 25:606-16. doi: 10.1016/j.clnu.2005.12.012

25. Rhee K-J, Lee CG, Kim SW, Gim D-H, Kim H-C, Jung BD. Extract of Ginkgo biloba ameliorates streptozotocin-induced type 1 Diabetes mellitus and high-fat diet-induced type 2 diabetes mellitus in mice. Int $J$ Med Sci. (2015) 12:987-94. doi: 10.7150/ijms.13339

26. Banin RM, Hirata BKS, Andrade IS, Zemdegs JCS, Clemente APG, Dornellas APS, et al. Beneficial effects of Ginkgo biloba extract on insulin signaling cascade, dyslipidemia, and body adiposity of diet-induced obese rats. Braz J Med Biol Res. (2014) 47:780-8. doi: 10.1590/1414-431X20142983

27. Hirata BKS, Banin RM, Dornellas APS, De Andrade IS, Zemdegs JCS, Caperuto LC, et al. Ginkgo biloba extract improves insulin signaling and attenuates inflammation in retroperitoneal adipose tissue depot of obese rats. Mediators Inflamm. (2015) 2015:419106. doi: 10.1155/2015/419106

28. Banin RM, de Andrade IS, Cerutti SM, Oyama LM, Telles MM, Ribeiro EB. Ginkgo biloba Extract (GbE) stimulates the hypothalamic serotonergic system and attenuates obesity in ovariectomized rats. Front Pharmacol. (2017) 8:605. doi: 10.3389/fphar.2017.00605

29. Dell'Agli M, Bosisio E. Biflavones of Ginkgo biloba stimulate lipolysis in 3T3-L1 adipocytes. Planta Med. (2002) 68:76-9. doi: 10.1055/s-2002-19876

30. Liou CJ, Lai XY, Chen YL, Wang CL, Wei CH, Huang WC. Ginkgolide C suppresses adipogenesis in 3T3-L1 adipocytes via the AMPK signaling pathway. Evid Based Complement Altern Med. (2015) 2015:298635. doi: $10.1155 / 2015 / 298635$

31. Oliveira DR, Sanada PF, Saragossa FAC, Innocenti LR, Oler G, Cerutti JM, et al. Neuromodulatory property of standardized extract Ginkgo biloba L. (EGb 761) on memory: behavioral and molecular evidence. Brain Res. (2009) 1269:68-89. doi: 10.1016/j.brainres.2008.11.105

32. Bolsoni-Lopes A, Festuccia WT, Chimin P, Farias TS, Torres-Leal FL, Cruz MM, et al. Palmitoleic acid (n-7) increases white adipocytes GLUT4 content and glucose uptake in association with AMPK activation. Lipids Health Dis. (2014) 13:199. doi: 10.1186/1476-511X-13-199

33. de Sá RD, Crisma AR, Cruz MM, Martins AR, Masi LN, do Amaral CL, et al. Fish oil prevents changes induced by a high-fat diet on metabolism and adipokine secretion in mice subcutaneous and visceral adipocytes. J Physiol. (2016) 594:6301-17. doi: 10.1113/JP272541

34. Randle PJ. Fat Cells. Nature. (1972) 237:521. doi: 10.1038/237521b0

35. Livak KJ, Schmittgen TD. Analysis of relative gene expression data using realtime quantitative PCR and the 2- $\Delta \Delta$ CT method. Methods. (2001) 25:402-8. doi: 10.1006/meth.2001.1262

36. Lieberman HR, Kellogg MD, Fulgoni VL, Agarwal S. Moderate doses of commercial preparations of Ginkgo biloba do not alter markers of liver function but moderate alcohol intake does: a new approach to identify and quantify biomarkers of 'adverse effects' of dietary supplements. Regul Toxicol Pharmacol. (2017) 84:45-53. doi: 10.1016/j.yrtph.2016.12.010

37. Ramassamy C, Longpré F, Christen Y. Ginkgo biloba extract (EGb 761) in alzheimers disease: is there any evidence? Curr Alzheimer Res. (2007) 4:253-62. doi: 10.2174/156720507781077304

38. Mahadevan S, Park Y. Multifaceted therapeutic benefits of Ginkgo biloba L.: chemistry, efficacy, safety, and uses. J Food Sci. (2008) 73:R14-9. doi: 10.1111/j.1750-3841.2007.00597.x

39. Buettner R, Schölmerich J, Bollheimer LC, Scholmerich J, Bollheimer LC. High-fat diets : modeling the metabolic disorders of human obesity in rodents. Obesity. (2007) 15:798-808. doi: 10.1038/oby.2007.608

40. Kubant R, Poon AN, Sánchez-Hernández D, Domenichiello AF, Huot PSP, Pannia E, et al. A comparison of effects of lard and hydrogenated vegetable shortening on the development of high-fat diet-induced obesity in rats. Nutr Diabetes. (2015) 5:1-6. doi: 10.1038/nutd.2015.40

41. Dornellas APS, Watanabe RLH, Pimentel GD, Boldarine VT, Nascimento CMO, Oyama LM, et al. Deleterious effects of lard-enriched diet on tissues fatty acids composition and hypothalamic insulin actions. Prostaglandins Leukot. Essent. Fat. Acids. (2015) 102-3:21-9. doi: 10.1016/j.plefa.2015. 10.003

42. Torres-Leal FL, Fonseca-Alaniz MH, Rogero MM, Tirapegui J. The role of inflamed adipose tissue in the insulin resistance. Cell Biochem Funct. (2010) 28:623-31. doi: 10.1002/cbf.1706

43. Yu YH, Ginsberg HN. Adipocyte signaling and lipid homeostasis: sequelae of insulin-resistant adipose tissue. Circ Res. (2005) 96:1042-52. doi: 10.1161/01.RES.0000165803.47776.38

44. Larson-Meyer E, Heilbronn LK, Redman LM, Newcomer BR, Frisard MI, Anton S, et al. Effect of calorie restriction with or without exercise on insulin 
sensitivity, beta-cell function, fat cell size, and ectopic lipid in overweight subjects. Diabetes Care. (2006) 29:1337-44. doi: 10.2337/dc05-2565

45. Lee M-J, Wu Y, Fried SK. Adipose tissue heterogeneity: implication of depot differences in adipose tissue for obesity complications. Mol Aspects Med. (2013) 34:1-11. doi: 10.1016/j.mam.2012.10.001

46. Andersson D, Löfgren P, Thorell A, Arner P, Hoffstedt J. Visceral fat cell lipolysis and cardiovascular risk factors in obesity. Horm Metab Res. (2011) 43:809-15. doi: 10.1055/s-0031-1287767

47. Ding S, Dudley E, Plummer S, Tang J, Newton RP, Brenton AG. Quantitative determination of major active components inGinkgo biloba dietary supplements by liquid chromatography/mass spectrometry. Rapid Commun Mass Spectrom. (2006) 20:2753-60. doi: 10.1002/rcm.2646

48. Priyanka A, Sindhu G, Shyni GL, Preetha Rani MR, Nisha VM, Raghu KG. Bilobalide abates inflammation, insulin resistance and secretion of angiogenic factors induced by hypoxia in 3T3-L1 adipocytes by controlling NF-KB and JNK activation. Int Immunopharmacol. (2017) 42:209-17. doi: 10.1016/j.intimp.2016.11.019

49. Cho Y, Park J, Jin H, Kim W, Ji M, Jang J, et al. Ginkgetin, a biflavone from Ginkgo biloba leaves, prevents adipogenesis through STAT5-mediated PPAR $\gamma$ and C / EBP $\alpha$ regulation. Pharmacol Res. (2019) 139:325-36. doi: 10.1016/j.phrs.2018.11.027

50. Seo Y, Kang O, Kim S, Mun S, Kang D, Yang D, et al. Quercetin prevents adipogenesis by regulation of transcriptional factors and lipases in OP9 cells. Int J Mol Med. (2015) 35:1779-85. doi: 10.3892/ijmm.2015. 2185

51. Saponara R, Bosisio E. Inhibition of cAMP-phosphodiesterase by biflavones of Ginkgo biloba in rat adipose tissue. J Nat Prod. (1998) 61:1386-7. doi: $10.1021 / \mathrm{np} 970569 \mathrm{~m}$

52. Kern PA, Gregorio GDI, Lu T, Rassouli N, Ranganathan G. Perilipin expression in human adipose tissue is elevated with obesity. J Clin Endocrinol Metab. (2004) 89:1352-8. doi: 10.1210/jc.2003-031388

53. Hotamisligil GS, Shargill NS, Spiegelman BM. Adipose expression of tumor necrosis factor-alpha: direct role in obesity-linked insulin resistance. Science. (1993) 259:87-91. doi: 10.1126/science.7678183
54. Berndt J, Kovacs P, Ruschke K, Klöting N, Fasshauer M, Schön MR, et al. Fatty acid synthase gene expression in human adipose tissue: association with obesity and type 2 diabetes. Diabetologia. (2007) 50:1472-80. doi: $10.1007 / \mathrm{s} 00125-007-0689-\mathrm{x}$

55. Kumar MV, Shimokawa T, Nagy TR, Lane MD. Differential effects of a centrally acting fatty acid synthase inhibitor in lean and obese mice. Proc Natl Acad Sci USA. (2002) 99:1921-5. doi: 10.1073/pnas.042683699

56. Mobbs CV, Makimura H. Block the FAS, lose the fat. Nat Med. (2002) 8:335-6. doi: 10.1038/nm0402-335

57. Loftus TM, Jaworsky DE, Frehywot GL, Townsend CA, Ronnett GV, Lane $\mathrm{MD}$, et al. Reduced food intake and body weight in mice treated with fatty acid synthase inhibitors. Science. (2000) 288:2379-81. doi: 10.1126/science.288.5475.2379

58. Liang Y, Tian W, Ma X. Inhibitory effects of grape skin extract and resveratrol on fatty acid synthase. BMC Complement Altern Med. (2013) 13:361. doi: 10.1186/1472-6882-13-361

59. Qiao Y, Sun J, Xia S, Tang X, Shi Y, Le G. Effects of resveratrol on gut microbiota and fat storage in a mouse model with high-fat-induced obesity. Food Funct. (2014) 5:1241. doi: 10.1039/c3fo60630a

60. Shimokawa T, Kumar MV, Lane MD. Effect of a fatty acid synthase inhibitor on food intake and expression of hypothalamic neuropeptides. Proc Natl Acad Sci USA. (2002) 99:66-71. doi: 10.1073/pnas.012606199

Conflict of Interest Statement: The authors declare that the research was conducted in the absence of any commercial or financial relationships that could be construed as a potential conflict of interest.

Copyright (c) 2019 Hirata, Cruz, de Sá, Farias, Machado, Bueno, Alonso-Vale and Telles. This is an open-access article distributed under the terms of the Creative Commons Attribution License (CC BY). The use, distribution or reproduction in other forums is permitted, provided the original author(s) and the copyright owner(s) are credited and that the original publication in this journal is cited, in accordance with accepted academic practice. No use, distribution or reproduction is permitted which does not comply with these terms. 